\title{
Revisions to China's GDP Data Following the 2004 Economic Census: More Questions Than Answers?
}

27 May 2006

Journal of Economic Literature classification codes: P27, O4, O53, C82

Keywords (all: China): national income accounting, growth estimates, benchmark revisions, economic census

Carsten A. Holz

Social Science Division, Hong Kong University of Science \& Technology

Clear Water Bay, Kowloon, Hong Kong

Tel/fax: +852 2719-8557

socholz@ust.hk; http://ihome.ust.hk/ socholz

On 9 January 2006, China's National Bureau of Statistics (NBS) announced a benchmark revision of GDP statistics for the years 1993-2004 based on the findings of the 2004 economic census. It released nominal values of GDP and sectoral value added (obtained following the production approach) for these years, as well as real growth rates. The new data have three important implications. (i) Despite all the hype only a few years ago about data falsification by local statistical authorities in China, and despite the NBS's efforts to correct local data when deriving national data, the 2004 economic census results validate the local data and invalidate the NBS data for the years 1993-2004. (ii) While (national) economywide as well as all sectoral nominal values were significantly revised upward following the 2004 economic census, real growth rates of some sectors remained unchanged, which is not plausible. (iii) The selective revisions to production approach data have implications for the as yet unpublished revisions to expenditure approach data (including investment) and income approach data (including labor remuneration and the profit measure operating surplus).

\section{Are the provincial data better than the national ones?}

National GDP should equal the sum of provincial GDP. But prior to the benchmark revision, the sum of provincial GDP routinely exceeded national GDP. Table 1 shows the extent of NBS adjustments to provincial data in the case of production approach GDP, i.e., for GDP obtained as the sum of value added across economic sectors. The discrepancy between the sum of provincial GDP and the NBS's national GDP figure increased from 1996 through 2004; by 2004, the sum of provincial GDP was $19.26 \%$ larger than the national value reported by the NBS. The NBS consistently revised downward provincial secondary sector and in particular tertiary sector value added.

The rising discrepancy coincided with a wave of reports on local data falsification in 1997 through approximately 2001. In response, the NBS, with support of the State Council and the Disciplinary Commission of the Chinese Communist Party Central Committee, in 1997/98 started a campaign against local data falsification. The continuing discrepancy between the national data and the sum provincial data all the way up through 2004 would suggest that the campaign was not successful. In 2004, the then NBS commissioner, Li Deshui, offered a mix 
of technical reasons and corrections of exaggerated data as explanation of the discrepancy: provinces use 1990 base year prices when calculating real growth, while the NBS makes adjustments to this procedure based on a price index (and starting in 2004 the NBS fully switched to a price index); provinces double-count cross-provincial economic activities; provinces still use (presumably questionable) report forms for industrial enterprises with annual sales revenue below 5m yuan RMB; provinces use the opportunity of the as yet incomplete measurement of tertiary sector activities to adjust tertiary sector output upward such that the sectoral data add up to their desired aggregate output value; and provinces have incentives to exaggerate output (due to growth targets, comparisons of different localities by their output growth rates, and the use of statistics to measure local cadres' "achievements").

Despite the NBS arguments in favor of the national rather than sum provincial data, the 2004 economic census with its subsequent benchmark revisions to the GDP values of 19932004 suggests that the provincial GDP values, and thereby the sum provincial value added, may in recent years have been more accurate than the national data. The second block of data in Table 1 shows the percentage increase of the revised nominal national values (following the 2004 economic census) over the pre-revision nominal national values (as previously published in the Statistical Yearbook 2005). The revised nominal GDP figure of 2004 is $16.8 \%$ higher than the originally published one, with most of this increase due to an almost $50 \%$ upward revision to tertiary sector value added. The annual revisions to primary sector value added across all years (1993-2004) remain below $1 \%$ and those of industry below 4\%, while construction value added was reduced by up to $9.2 \%$.

Contrary to NBS commissioner Li Deshui's explanation of the discrepancy between national and sum provincial data, the 2004 economic census results imply that provinces did not over-report tertiary sector value added. If the 2004 economic census results are correct, provinces under-reported tertiary sector value added, had the correct data for the primary sector, and over-reported slightly in industry and strongly in (the small sector) construction. Overall, the sum of original and so far not revised provincial GDP in 2004 was only 2.1\% larger than the revised national figure (third block of data in Table 1). The previously published national figure, on the other hand, was $14 \%$ too low (the benchmark revision $16.8 \%$ higher than the previously published national figure).

\section{Fudging deflators in order not to have to revise real growth rates to undesirable levels?}

Table 2 presents three real growth rate series. These are the pre-revision real growth rates (as published in the Statistical Yearbook 2005), the revised ones (following the 2004 economic census), and a here newly constructed mixed one which uses the revised nominal data and the sectoral deflators implicit in the Statistical Yearbook 2005 data. The implicit deflators are calculated in the latter instance because the NBS does not publish its GDP deflators. The Statistical Yearbook reports nominal sectoral value added as well as sectoral real growth rates, usually for the years since 1978. The implicit deflator follows directly from nominal values combined with real growth rates. ${ }^{1}$

\footnotetext{
1 Sectoral real growth rates are aggregated into GDP real growth rates using a Tornqvist index (with industry first aggregated to the secondary sector, and then the three main economic sectors aggregated to GDP). The presentation here ignores that the NBS in the Statistical Yearbook for each year first offers the preliminary nominal data with a real growth rate for the latest year, and in the next issue provides the final (revised) nominal data for that particular year but usually does not revise the originally published real growth rate. I.e., in the annual revisions embedded in the Statistical Yearbook series, the NBS already once implicitly revised the
} 
In the revised GDP data released following the 2004 economic census, the revised real growth rates in the primary sector as well as in the secondary sector (including separate data on both industry and construction) are all identical to the previously published real growth rates (in the Statistical Yearbook 2005). This means that what the NBS has done in all sectors except in the tertiary sector is to change the deflators to exactly match the revised nominal values. I.e., it raised the implicit deflators of the primary sector and of industry, and lowered that of construction.

There are two possible interpretations of this pattern. One, the NBS used the opportunity of the 2004 economic census to in these two sectors switch to a new deflator. But it seems unlikely that the nationwide collection of comprehensive data changes a deflator and nothing else; the census was not about deflators for the years 1993-2004, but about year 2004 output (and other economic measures for 2004). This would imply that the NBS has not made use of 2004 economic census data in these two sectors. Was the 2004 economic census of such poor quality that its data for the primary and secondary sector were unusable? Or were the census results perfectly identical to the original data (which would make the census in these sectors redundant)?

The second possible interpretation is that the NBS did not want to increase the real growth rates in these two sectors and therefore simply changed the implicit deflators.

The fact that the NBS retained its secondary sector real growth rate is also problematic. It implies that the NBS did not change the weights of industry and construction in the calculation of secondary sector real growth rates, despite the increase in nominal value added of industry and the decrease in nominal value added of construction, and even though these changes are sufficiently large to in some years change the real growth rate of the secondary sector, calculated with one decimal and using a Tornqvist index or previous-year weights. This appears an outright mistake.

In sum, because the NBS is unlikely to have available new price data in its annual revisions or in the 2004 benchmark revision (with supposedly new deflators for 1993-2004), these discrepancies reflect a decision by the NBS to by and large not let revisions to nominal data find their way into revisions to real growth rates. This is done by adjusting the deflators of agriculture, industry, and construction in a very peculiar way (to exactly match changes to the nominal data) and by ignoring the changing weights of the real growth rates of industry and construction.

With only the tertiary sector real growth rates allowed to increase (together with the tertiary sector implicit deflators), the overall effect on real GDP growth is smaller than the increase in nominal 2004 GDP of $16.8 \%$ over the previously published figure would suggest. The pre-revision official average annual real growth rate between 1992 and 2004 is $9.4 \%$, the revised official one following the 2004 economic census is $9.9 \%$, but a revised real growth

sectoral deflators of all years except of the most recent year. Annual revisions to the deflators are not plausible because the data that underlie the deflators are available when the nominal data are first published, and are not subject to later revisions. On average, between 1978 and 2004, the NBS revised the implicit deflators slightly upward. The revised implicit deflators in the Statistical Yearbook 2005 are used in the following in order not to complicate matters further. Using the (unrevised) implicit deflators as first published would make only a small difference to what follows. 
rate based on the revised nominal data and the original implicit GDP deflator (in the Statistical Yearbook 2005) would have been 10.7\%.

\section{Creating havoc across the whole body of statistical data?}

In the expenditure approach to the calculation of GDP, an alternative to the production approach, GDP equals consumption by households and government, gross fixed capital formation (a measure of investment), changes to inventories, and net exports. The NBS has not yet released revised expenditure approach data. In the income approach, a yet third approach, GDP equals labor remuneration, depreciation, net taxes on production, and operating surplus (a measure of profit); the NBS has so far never reported national income approach data, but provincial-level data are available since 1978, in most years with identical provincial income approach and production approach GDP values. Revised provincial income approach data are also not yet available

The official calculation of national household consumption in the expenditure approach to the calculation of GDP has been problematic all along (Holz, 2004). It remains to be seen how the NBS will perform the daunting task of consistently and plausibly revising past national expenditure approach data, which in themselves appear derived from the underlying data in inconsistent fashion. In 2004 alone, an additional 16.8\% nominal GDP will have to be distributed in the expenditure approach (and less in the income approach, because provincial data were higher, in the aggregate, than national data all along).

The NBS's trick of only revising tertiary sector real growth rates (together with the tertiary sector implicit deflators, as in the other sectors) may facilitate the revisions to expenditure and income approach data, in that the NBS could somewhat plausibly focus on revising household consumption and labor remuneration data only, corresponding perhaps most to tertiary sector activities. In the expenditure approach, it could again retain old real growth rates and apply corrections to the deflators only (in the income approach, with only provincial nominal data, no real growth rates are published). But because the deflators in the expenditure approach consist mostly of published price indices, and because provincial and national data need to be consistent, the revisions will be far from trivial. The investment in fixed asset deflator and the Consumer Price Index, and thereby the bulk of China's price indices, would all be affected.

\section{Conclusions}

The fact that the 2004 economic census validated original provincial GDP data and invalidated original national GDP data raises severe questions about the capacity of the NBS to accurately compile national data. It retrospectively questions the existence, or at least the seriousness, of the supposed "wind of falsification and embellishment" that was claimed to rage across China in the late 1990s. (Was this only a ploy by the NBS to strengthen its hand against provincial governments and central ministries in a bureaucratic power struggle?)

In recent years, the NBS has repeatedly dropped hints of under-reported national tertiary sector value added, which suggests it knowingly reported false GDP data for at least the most recent years. The fact that the NBS did not use the 2004 economic census data on the primary and secondary sector to revise the primary and secondary sector real growth rates could be 
interpreted as the census being of poor quality (what a waste of money and effort!) in comparison to the NBS's annual efforts, or of political(?) decisions taking precedence over accuracy in statistical data. We will have to wait for an explanation by the NBS as to why it chose to revise only the implicit deflator of sectors that account for almost two-thirds of GDP. We may not get one.

The scope of revisions that the 2004 economic census implies is enormous, and the vast bulk of it has not (yet?) been made public. What is potentially affected includes the consumption statistics in the national income accounts, retail sales, household survey statistics, the whole range of investment statistics (with gross fixed capital formation in the national income accounts), wage statistics and welfare statistics, profit in the national income accounts, and the whole range of price indices. Having to somehow find $16.8 \%$ "more" in 2004 across a range of economic variables appears a severe embarrassment. The only consolation is that a 16.8\% upward revision in 2004, once spread over 12 years (1993-2004), amounts to little more than one percentage point every year.

\section{References}

Economic Census 2004. “Jingji pucha hou zhongguo GDP shuju jiedu zhi yi: GDP zongliang, zengzhang sudu ji renjun GDP” (China’s GDP figures after the economic census, part 1: GDP volume, GDP increase, and per capita GDP), 8 March 2006, available on the NBS website at http://www.stats.gov.cn/zgjjpc/cgfb/ (accessed on 27 April 2006). More data are contained in an earlier NBS announcement, "Guanyu wo guo guonei shengchan zongzhi lishi shuju xiuding jieguo de gonggao" (Announcement of the results of the historic revisions of China's GDP data), 9 Jan. 2006, also available on the NBS website at http://www.stats.gov.cn/tjdt/zygg/t20060109_402300176.htm (accessed on 27 April 2006).

Holz, Carsten A. “Deconstructing China’s GDP Statistics.” China Economic Review 15, no. 2 (2004a): 164-202.

Li Deshui. "Guanyu GDP de ji dian sikao" (Some considerations on GDP). Jingji yanjiu, no. 4 (2004): 26-8.

Statistical Yearbook. Zhongguo tongji nianjian (China Statistical Yearbook). Beijing:

Zhongguo tongji chubanshe, various years starting with the 1981 issue (1981 in the title), and since published annually, with the second issue labeled "1983." 
Table 1. Economic Census 2004 Results

\begin{tabular}{|c|c|c|c|c|c|c|}
\hline & GDP & $\begin{array}{l}\text { Primary } \\
\text { sector }\end{array}$ & $\begin{array}{l}\text { Secondary } \\
\text { sector }\end{array}$ & $\begin{array}{c}\# \\
\text { Industry }\end{array}$ & $\begin{array}{c}\# \\
\text { Construction }\end{array}$ & $\begin{array}{l}\text { Tertiary } \\
\text { sector }\end{array}$ \\
\hline \multicolumn{7}{|c|}{ Sum provincial (originally published) values divided by original national value } \\
\hline 1993 & 1.09 & 1.03 & 1.00 & 1.00 & 1.02 & 1.31 \\
\hline 1994 & 1.01 & 0.98 & 1.01 & 1.02 & 0.95 & 1.02 \\
\hline 1995 & 0.99 & 1.00 & 0.96 & n.a. & n.a. & 1.03 \\
\hline 1996 & 1.00 & 1.00 & 0.95 & 0.96 & 0.89 & 1.08 \\
\hline 1997 & 1.03 & 1.05 & 0.98 & 0.99 & 0.90 & 1.09 \\
\hline 1998 & 1.04 & 1.02 & 1.00 & 1.00 & 0.99 & 1.12 \\
\hline 1999 & 1.07 & 1.01 & 1.01 & 1.00 & 1.04 & 1.19 \\
\hline 2000 & 1.09 & 1.04 & 1.01 & 1.00 & 1.07 & 1.23 \\
\hline 2001 & 1.11 & 1.06 & 1.02 & 1.01 & 1.09 & 1.28 \\
\hline 2002 & 1.13 & 1.01 & 1.04 & 1.02 & 1.14 & 1.32 \\
\hline 2003 & 1.16 & 1.01 & 1.08 & 1.07 & 1.18 & 1.34 \\
\hline 2004 & 1.19 & 1.01 & 1.14 & 1.13 & 1.21 & 1.37 \\
\hline \multicolumn{7}{|c|}{$\begin{array}{l}\text { Percentage difference in economic census values vs. previously published national } \\
\text { values (in the Statistical Yearbook 2005) }\end{array}$} \\
\hline 1993 & 2.0 & 0.1 & 0.2 & 0.3 & -0.8 & 5.9 \\
\hline 1994 & 3.1 & 0.1 & 0.3 & 0.6 & -1.6 & 9.0 \\
\hline 1995 & 4.0 & 0.2 & 0.5 & 0.9 & -2.4 & 12.0 \\
\hline 1996 & 4.8 & 0.3 & 0.7 & 1.3 & -3.2 & 14.8 \\
\hline 1997 & 6.1 & 0.4 & 0.9 & 1.6 & -3.9 & 18.0 \\
\hline 1998 & 7.7 & 0.5 & 1.0 & 1.9 & -4.7 & 22.3 \\
\hline 1999 & 9.3 & 0.5 & 1.2 & 2.2 & -5.5 & 26.1 \\
\hline 2000 & 10.9 & 0.6 & 1.4 & 2.5 & -6.2 & 30.2 \\
\hline 2001 & 12.7 & 0.7 & 1.6 & 2.8 & -6.9 & 34.6 \\
\hline 2002 & 14.4 & 0.8 & 1.7 & 3.2 & -7.7 & 39.1 \\
\hline 2003 & 15.7 & 0.8 & 1.9 & 3.5 & -8.4 & 43.7 \\
\hline 2004 & 16.8 & 0.9 & 2.1 & 3.8 & -9.2 & 48.7 \\
\hline \multicolumn{7}{|c|}{$\begin{array}{l}\text { Percentage difference in economic census values v. sum provincial (originally } \\
\text { published) values }\end{array}$} \\
\hline 1993 & 3.2 & 0.7 & 0.9 & 0.2 & 5.6 & 8.1 \\
\hline 1994 & 6.2 & 2.2 & 4.2 & 3.7 & 8.1 & 11.7 \\
\hline 1995 & 5.5 & 0.6 & 6.3 & n.a. & n.a. & 7.4 \\
\hline 1996 & 3.8 & -0.4 & 6.0 & 5.5 & 9.3 & 3.2 \\
\hline 1997 & 2.6 & -2.4 & 4.1 & 4.3 & 2.5 & 3.4 \\
\hline 1998 & 2.0 & -1.7 & 1.1 & 2.0 & -4.7 & 5.0 \\
\hline 1999 & 2.3 & -0.5 & 0.7 & 2.2 & -8.9 & 5.6 \\
\hline 2000 & 2.1 & -0.9 & -0.5 & 1.4 & -12.4 & 6.5 \\
\hline 2001 & 2.7 & -0.2 & -0.7 & 1.7 & -15.5 & 7.9 \\
\hline 2002 & 2.0 & 0.1 & -3.0 & -0.3 & -19.0 & 8.6 \\
\hline 2003 & 0.2 & -0.6 & -6.0 & -3.2 & -22.3 & 8.4 \\
\hline 2004 & -2.1 & 0.3 & -10.4 & -7.9 & -25.1 & 8.5 \\
\hline
\end{tabular}

\# denotes a sub-category

Sources and explanations: Economic Census 2004 (announcement of 9 Jan. 2006, with original and revised nominal values). Previously (pre-revision) published national values: Statistical Yearbook 2005, p. 51. Originally published national and provincial values from each year's issue of the Statistical Yearbook (provincial values are never revised in the Statistical Yearbook); the 1993 provincial values incorporate the 1993 benchmark revisions following the 1991/92 tertiary sector census, while the original national values do not. 
Table 2. Original Vs. Revised Real Growth Rates (2004 Economic Census)

\begin{tabular}{|c|c|c|c|c|c|c|c|c|c|}
\hline & \multicolumn{3}{|c|}{ GDP } & \multicolumn{3}{|c|}{ Primary sector } & \multicolumn{3}{|c|}{ Secondary sector } \\
\hline & Prev. & Rev. & Mix & Prev. & Rev. & Mix & Prev. & Rev. & Mix \\
\hline 1993 & 13.5 & 14.0 & 15.9 & 4.7 & 4.7 & 4.8 & 19.9 & 19.9 & 20.0 \\
\hline 1994 & 12.6 & 13.1 & 13.7 & 4.0 & 4.0 & 4.1 & 18.4 & 18.4 & 18.4 \\
\hline 1995 & 10.5 & 10.9 & 11.3 & 5.0 & 5.0 & 5.1 & 13.9 & 13.9 & 14.0 \\
\hline 1996 & 9.6 & 10.0 & 10.3 & 5.1 & 5.1 & 5.2 & 12.1 & 12.1 & 12.2 \\
\hline 1997 & 8.8 & 9.3 & 9.7 & 3.5 & 3.5 & 3.6 & 10.5 & 10.5 & 10.4 \\
\hline 1998 & 7.8 & 7.8 & 9.2 & 3.5 & 3.5 & 3.6 & 8.9 & 8.9 & 9.1 \\
\hline 1999 & 7.1 & 7.6 & 8.4 & 2.8 & 2.8 & 2.9 & 8.1 & 8.1 & 8.2 \\
\hline 2000 & 8.0 & 8.4 & 9.2 & 2.4 & 2.4 & 2.5 & 9.4 & 9.4 & 9.5 \\
\hline 2001 & 7.5 & 8.3 & 9.2 & 2.8 & 2.8 & 2.9 & 8.4 & 8.4 & 8.7 \\
\hline 2002 & 8.3 & 9.1 & 10.0 & 2.9 & 2.9 & 3.0 & 9.8 & 9.8 & 10.1 \\
\hline 2003 & 9.5 & 10.0 & 10.9 & 2.5 & 2.5 & 2.6 & 12.7 & 12.7 & 12.9 \\
\hline \multirow[t]{3}{*}{2004} & 9.5 & 10.1 & 11.0 & 6.3 & 6.3 & 6.4 & 11.1 & 11.1 & 11.3 \\
\hline & \multicolumn{3}{|c|}{ \# Industry } & \multicolumn{3}{|c|}{ \# Construction } & \multicolumn{3}{|c|}{ Tertiary sector } \\
\hline & Prev. & Rev. & Mix & Prev. & Rev. & Mix & Prev. & Rev. & Mix \\
\hline 1993 & 20.1 & 20.1 & 20.5 & 18.0 & 18.0 & 17.0 & 10.7 & 12.1 & 17.2 \\
\hline 1994 & 18.9 & 18.9 & 19.3 & 13.7 & 13.7 & 12.8 & 9.6 & 11.0 & 12.9 \\
\hline 1995 & 14.0 & 14.0 & 14.4 & 12.4 & 12.4 & 11.5 & 8.4 & 9.8 & 11.3 \\
\hline 1996 & 12.5 & 12.5 & 12.8 & 8.5 & 8.5 & 7.6 & 7.9 & 9.4 & 10.7 \\
\hline 1997 & 11.3 & 11.3 & 11.6 & 2.6 & 2.6 & 1.8 & 9.1 & 10.7 & 12.1 \\
\hline 1998 & 8.9 & 8.9 & 9.2 & 9.0 & 9.0 & 8.1 & 8.3 & 8.3 & 12.3 \\
\hline 1999 & 8.5 & 8.5 & 8.8 & 4.3 & 4.3 & 3.4 & 7.7 & 9.3 & 11.1 \\
\hline 2000 & 9.8 & 9.8 & 10.1 & 5.7 & 5.7 & 4.9 & 8.1 & 9.7 & 11.6 \\
\hline 2001 & 8.7 & 8.7 & 9.0 & 6.8 & 6.8 & 6.0 & 8.4 & 10.2 & 12.1 \\
\hline 2002 & 10.0 & 10.0 & 10.3 & 8.8 & 8.8 & 7.9 & 8.7 & 10.4 & 12.4 \\
\hline 2003 & 12.8 & 12.8 & 13.2 & 12.1 & 12.1 & 11.2 & 7.8 & 9.5 & 11.3 \\
\hline 2004 & 11.5 & 11.5 & 11.8 & 8.1 & 8.1 & 7.2 & 8.3 & 10.0 & 12.1 \\
\hline
\end{tabular}

\# denotes a sub-category

Prev.: pre-revision real growth rates as published in the Statistical Yearbook 2005.

Rev.: revised values real growth rates following the 2004 economic census.

Mix: revised nominal values from 2004 economic census combined with implicit deflators from Statistical Yearbook 2005; secondary sector real growth rates are aggregates of industry and construction real growth rates (using a Tornqvist index, with 2004 economic census nominal values for weights); real GDP growth rates are aggregates of the three main economic sectors.

Sources: Economic census 2004 (9 Jan. 2006); Statistical Yearbook 2005, pp. 51, 53. 